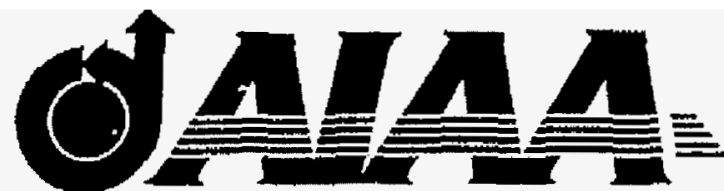

AIAA-94-3010

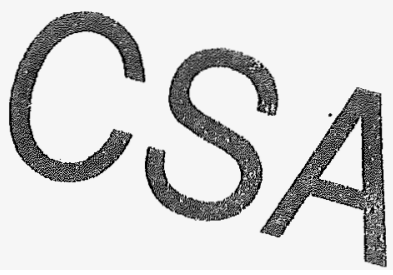

Experimental Evaluation of Russian Anode Layer Thrusters

C.E. Garner, J. R. Brophy, 3. E. Polk

Jet Propulsion Laboratory

California Institute of Technology

Pasadena, CA

S. Semenkin and V. Garkusha

Central Research Institute of Machine Building

Kaliningrad (Moscow Region), Russia

S. Tverdokhlebov

TsNIIMASH-Export

Kaliningrad (Moscow Region), Russia

C. Marrese

University of Michigan

Ann Arbor, MI

\section{0th AIAA/ASME/SAE/ASEE Joint Propulsion Conference June 27-29, 1994 / Indianapolis, IN}


AIAA-94-3010

\title{
Experimental Evaluation of Russian Anode Layer Thrusters
}

\author{
Charies E. Gamer, *John R. Brophy,** and James E. Polk* \\ Jet Propulsion Laboratory \\ Pasadena, California \\ Sasha Semenkin ${ }^{* *}$ and Valery Garkushat \\ Central Research Institute of Machine Building \\ Kaliningrad (Moscow Region), Russia \\ Sergey Tverdokhlebovtt \\ TsNIIMASH-Export \\ Kaliningrad (Moscow Region), Russia \\ Colleen Marrese \\ University of Michigan \\ Ann Arbor, Michigan
}

\begin{abstract}
Performance and endurance testing of ti $1.35 \mathrm{~kW}$ thruster with anode layer (TAL) developed at the Central Research Institute of Machine Building (TsNIIMASH) is described. The TAL evaluated herein Is designated the $\mathbf{D}-\$ 5$ and is characterized by an external acceleration zone to maximize engine life. Performance measurements indicate that the D-\$5 performance is comparable to that of the SPT-100 for operation at $1.35 \mathrm{~kW}$. A 636 hour accelerated wear test was performed to assess the thruster service life capability. For this test the TsNIIMASH cathode was replaced by a cathode fabricated at JPL to eliminate concerns over cathode durability since the primary objective was to evaluate the discharge chamber erosion characteristics. Post test examination indicated that the volume of material removed over the course of the wear test was approximately an order of magnitude less than for the SPT-100 over the same operating duration. Most of the engine erosion takes place on guard rings which protect the magnetic circuit pole pieces from erosion. Changing this ring material from stainless steel to a more sputter-resistant material, such as graphite, will further reduce the erosion rate and yield engine life times estimated to be greater than 5,000 hours.
\end{abstract}

\section{Introduction}

Hall thrusters have generated a great deal of interest world-wide since the introduction of the Russian stationary plasma thruster, SPT-100, to the West at the beginning of this decade. Performance evaluations $[3,2]$ and on-going endurance tests $[3,4]$ continue to support claims that the SPT-100 thruster is a robust device with excellent operating characteristics. A different type of Hall thruster, the thruster with anode layer (TAL), also developed in

*Member of the Technical Staff, Member AIAA

**Group Supervisor

†Head of Department

t†Executive Director

$\ddagger$ Undergraduate Student
Russia, has performance characteristics which are comparable to those of the stationary plasma thruster [5], For the same power level, however, the TAL discharge chamber is physically smaller than that of the SPT. The D-55 TAL, for example, has a nominal operating power level of $1.35 \mathrm{~kW}$ and a characteristic discharge chamber diameter of only $75 \mathrm{~mm}$ or approximately $3 / 4$ of the characteristic dimension of the $100 \mathrm{~mm}$ diameter $1.35 \mathrm{~kW}$, SPT. 100. Never-the-less, in spite of the increased thrust density corresponding to its small physical size, there is reason to believe that the TAL with "external layer" may have erosion characteristics superior to the SPT.

For this reason the Ballistic Missile Defense Organization (BMDO) has sponsored a program to evaluate the rerformance, erosion characteristics and integration issues associated with the anode layer 
thruster [6]. The program is being executed primarily by NASA Lewis Research Center (LeRC) and the Jet Propulsion Laboratory (JPL) in cooperation with the Central Research Institute for Machine Building (TsNITMASH) in Kaliningrad (Moscow region), Russia. Performance testing and evaluation of integration issues are being performed at LeRC [7], while performance and endurance testing is being done at JPL. Two types of anode layer thrusters were purchased from TsNIIMASH, the $1.35 \mathrm{~kW} \mathrm{D-55}$ and the $4.5 \mathrm{~kW} \mathrm{D-100.} \mathrm{This}$ paper describes the performance and endurance testing of the D-55 TAL at JPL.

\section{Historical Background}

The physical principle of the thruster with anode layer was first proposed by A. V Zharinov more than 30 years ago $[8,9,10]$. Work at TsNIIMASH in the early 1960 s under his guidance emphasized understanding the fundamental physics of anode layer thruster operation. Members of Zharinov's team included Bvgeny Lyapin, V. S. Erofeev, M. A. Abdukhanov, and Yu. S. Popov. The TAL research at TsNIIMASH was part of a larger program to investigate a wide variety of plasma accelerators under the supervision of S. D. Grishin.

Early development of the anode layer thruster concentrated on the double-stage thruster $[11,12]$ The first stage in this thruster is a low voltage discharge with closed Hall current used for ion generation. In the second stage of the engine the ions are accelerated by the electric field of the anode layer produced in the transverse magnetic field. Such engines were designed for application to Solar System exploration spacecraft and have specific impulses ranging from 2,000 to $8,000 \mathrm{~s}$,

By the end of the 1960s a double-stage TAL using bismuth as the propellant had been operated at up to $100 \mathrm{~kW}$ with a specific impulse of $8,000 \mathrm{~s}$ and a total efficiency of close to $0.8[12,13]$. Wear tests of a few hundred to a thousand hours indicated an engine lifetime of a few thousand hours [14]. Cesium and xenon propellant were also investigated.

By the $1970 \mathrm{~s}$, thruster development had outpaced the availability of high power levels in space and the program was redirected to emphasize the development of low $(-1 \mathrm{~kW})$ and medium $(-10$ $\mathrm{kW})$ power level thrusters operating on rare gases (especially xenon). Research efforts centered on the development of a single-stage anode layer thruster $[15,16]$, and also on understanding the thruster dynamic characteristics $[17,18,19]$ and service life capabilities $[16,20]$. The product of this effort was the high efficiency, single-stage anode layer thruster $[20,21]$.

To achieve long thruster lifetimes, one of the principal innovations was the development of the TAL with external layer in which the ion production and ion acceleration regions actually exist just downstream of the exit plane of the thruster. This configuration greatly reduces the flux of energetic ions to thruster surfaces thereby significantly reducing the erosion of those surfaces.

\section{Apparatus and Procedure}

The single-stage, D-55 TAL, shown in Fig. 1, consists of an annular discharge chamber in which the anode electrode extends nearly to the exit plane of the thruster as suggested in Fig. 2. In a fashion similar to the SPT, a radial magnetic field is established across the annular discharge chamber through the use of electromagnets. The strength of the magnetic field is sufficient to magnetize the electrons but not the ions. Tailoring of the magnetic field is accomplished through a proprietary design which concentrates the magnetic flux density in the region of space just beyond the anode, This in turn establishes most of the anode to cathode voltage difference in this region, which is roughly half of the axial length of that in the SPT-100.

An external cathode is used to supply electrons to the discharge chamber, as well as neutralize the ion beam. During normal operation most of the applied voltage difference between the anode and the cathode appears in a relatively thin layer adjacent to the anode. In the modern version of the single-stage TAL, this layer exists.just downstream of the exit plane of the thruster and the thruster is referred to as a TAL with external Iayer. By positioning the ionization and acceleration zone downstream of the discharge chamber walls, erosion of the thruster is minimized.

Surrounding the OD of the anode is a guard ring (see Fig. 2) designed to protect the steel magnetic circuit pole piece from ion sputtering. A similar guard ring is positioned inside the ID of the anode. The separation between the guard rings, which are at cathode potential, and the anode is approximately $0.97 \mathbf{m m}$ for the outer ring and $\mathbf{1 . 1 4}$ $\mathrm{mm}$ for the inner one. A possible failure mechanism for the thruster is shorting of the anode to the guard ring by a flake of sputter deposited material. In the thruster tested at JPL the guard rings were fabricated from stainless steel. It is recognized that substitution of a more sputterresistant material, such as graphite, would substantially increase the thruster life. The use of 
stainless steel in the thruster for the endurance test results in an accelerated erosion test in that the erosion characteristics obtained over a relative short time with stainless steel should be representative of much longer operation with graphite.

The heaterless cathode consists of a $\mathrm{LaB}_{6}$ emitter in a tantalum tube, A starter electrode positioned adjacent to the cathode is used only during startup. Little effort has been expended at TsNIMASH in the development and optimization of hollow cathodes since this technology already exists at other Russian organizations (Fakel Design Bureau forexample, makers of the SPT-100 hollow cathodes).

The D-55 laboratory model thruster also did not come with a flow splitter or flow control hardware, so independent control of the main and cathode flow rates was accomplished manually.

\section{Test Facility}

$\mathrm{AH}$ testing of the D-55 thruster was performed in a 2.4-m dia. $x$ 5-m stainless steel vacuum chamber equipped with oil diffusion pumps, with an effective pumping speed on xenon of approximately $14,000 \mathrm{~L} / \mathrm{s}$. A radiation cooled, graphite beam target was positioned at the end of the vacuum chamber opposite the thruster. In addition, the side walls of the chamber were also lined in graphite to minimize the rate of material backsputtered to the thruster.

A laboratory propellant feed system was assembled and carefully leaked checked. The micrometer valves controlling the main and cathode flow rates are positioned inside the vacuum chamber. The xenon feed pressure is dropped across the micrometer valves from $200 \mathrm{kPa}$ (29 psig) to a few torr or less for the engine. Since the feed pressure is above atmospheric pressure, this arrangement guarantees that no air can ieak into the propellant feed system. Rotary vacuum feed throughs are used to adjust the micrometer valves from outside the vacuum chamber.

A schematic diagram of the power supply configuration is shown in Fig. 3. Laboratory power supplies are used for all functions. The main run supply is a $12-\mathrm{kW}$, custom Spellman high voltage supply. Laboratory power supplies were used for both the cathode tip heater and for the cathode starter. A data acquisition and control system using LabView software and National Instruments hardware was used to record the operating data and permit unattended operation.
Thruster performance was measured using a modified' version of the inverted pendulum type thrust stand developed at NASA LeRC [22] Thrust stand calibrations are performed in situ and under computer control. Generally $\mathbf{4 0}$ to $\mathbf{8 0}$ calibrations are performed autonomously in order to obtain a large enough sampling for statistical analyses. Repeatability of the calibrations were normally $0.6 \%$ or better. During thruster operation, the thrust stand inclination is corrected every $3 \mathrm{~s}$ by the computer. To get the most accurate thrust measurements it is necessary to shut off the thruster. The thrust is determined by the difference in thrust stand LVDT signals with the thruster on and off, This approach minimizes any effects due to long term thrust stand zero drifts. In the course of the wear test the thruster was shut off approximately once every $\mathbf{2 4}$ hours to get an accurate thrust measurement.

\section{JPL Cathode}

Engine performance was measured with two different cathodes, the $\mathrm{LaB}_{6}$ cathode from TSNIMASH and a cathode fabricated at JPL. The JPL cathode consists of a 6.4-mm diameter molybdenum tube with a barium oxide impregnated porous tungsten insert. A $2 \%$ thoriated tungsten orifice plate, with an orifice diameter of $1.3 \mathrm{~mm}$ is eiectron-beam welded to the downstream end. A tantalum-sheathed tantalum heater wire is wrapped around the molybdenum tube to form the tip heater. An "enclosed keeper" starter electrode made of graphite surrounds the cathode. The endurance test was performed with the JPL cathode.

\section{Performance Results}

Engine efficiency as a function of input power is given in Fig. 4 These data suggest an engine performance which is comparable to that of the SPT 100 thruster.

\section{Endurance Test}

To investigate the erosion characteristics and evaluate the prospects for achieving a useful service life of several thousand hours, a 500 hour wear test at $1.35 \mathrm{~kW}$ was planned. At the completion of 500 hours the engine was operating so well that it was decided to continue the test. A photograph of the D-55 taken during the wear test is shown in Fig. 5. The glowing regions evident in this photograph are believed to be sputter deposits on the anode. The extent of these glowing regions grew steadily over the duration of the wear test. The thruster performed reliability for most of the wear test. On two cycles, however, a high current transient 
exceeding $20 \mathrm{~A}$ occurred causing the discharge to extinguish and terminating the cycle.

The test was terminated after 636 hours of operation when the thrust stand tilt mechanism failed. Without the ability to accurately measure the thmst it was decided to terminate the test and examine the condition of the thruster. The post-test condition of the thruster is shown in Figs. 6 and 7. The erosion of discharge chamber components is difficult to see both in this photograph and on the actual hardware.

\section{Performance History}

The thrust, discharge voltage, discharge current, mass flow rate and floating voltage are given in Fig. 8 as a function of time over the wear test. The floating voltage is the potential difference between the cathode and facility ground. The engine/power supply combination is operated ungrounded as indicated in Fig. 3. The data in Fig. 8 indicate essentially no change in the engine performance over the wear test. The scatter in the data over the first 20 hours was due to changes in operating conditions as the thruster performance envelope was explored.

\section{Discharge Oscillations}

Oscillations in the discharge current and voltage were recorded for each cycle using a digital oscilloscope. The data in Figs. 9a,b\&c were taken near the end of cycles 95 (run hour 25.9) and 126 (run hour 600). The discharge oscillations were measured in two different ways, and both are presented here, In the first way the "average" mode of the oscilloscope generates a trace by averaging 12 separate traces. In the second way, the "high resolution" mode was used to provide singlesweep traces. The high resolution mode results for cycle 126 are given in Fig. $9 \mathrm{a}$ and the corresponding average mode trace in Fig. 9c. The high resolution mode indicates slightly larger peak current oscillations (note the scale change between Figs. $9 b \& c)$.

The oscilloscope traces clearly indicate that there was no substantial change in current and voltage oscillations from the start to the end of the wear test (as seen by comparing Figs. 9a\&b). Current oscillations approached 9 A peak-to-peak, a level similar to that measured with the SPT-100 thruster, but voltage oscillations are almost nonexistent.

\section{BEAM PROFILES}

Beam profiles were measured using a single Faraday button probe mounted to a motorized arm which could swing the probe through an arc $0.86 \mathrm{~m}$ in radius from the thruster. The Faraday probe surface was covered with plasma sprayed tungsten to minimize secondary electron emission effects. A comparison of beam profiles taken at cycles of 95 and 128 is given in Fig. 10. These data indicate essentially no change in the beam shape over the course of the wear test. Since essentially no significant erosion of the magnetic circuit pole pieces occurred during this test, the shape and strength of the magnetic field should not have changed, which is consistent with a constant beam current density profile,

\section{Erosion Results}

During the 636 hours that the thruster was run, a dark gray material was deposited on the anode. Material analysis by EDAX indicated that the primary elements of the deposits are the constituents of stainless steel, carbon, molybdenum and xenon. The carbon is most likely backsputtered material from the graphite beam target and the stainless steel is probably from the guard rings. The xenon is obviously trapped propellant and the molybdenum is from the anode and was found only on the side of the deposits adjacent to the anode surface. The deposits were greatest on the anode and barely noticeable on the other thruster components. The maximum thickness of the deposited material was $11 \mu \mathrm{m}$. The entire anode appeared to be covered by a layer of this material except for an area of about $242 \mathrm{~mm}^{2}$ on the back wall of the anode located near the position of the cathode. In this region, the anode seemed to be covered with a thin oxide layer, giving the material a discolored appearance.

Erosion of the inner and outer guard rings was caused by ion sputtering, which resulted in modifying the shape of the ring covers (Figs. 11). The erosion depth in the direction parallel to the thruster axis of the outer guard ring is given in Fig. 12 as a function of clock angle (see Fig. 7 for the definition of zero degrees) for three different radial distances from the thruster axis. These erosion data appear to have a roughly sinusoidal shape with the minimum erosion depths occurring at the clock angles corresponding to the locations of the electromagnets, The maximum measured erosion depth on the outer guard ring was $1.25 \mathrm{~mm}$ (49.6 mils). 
Similar erosion depth measurements for the inner guard ring are given in Fig. 13 also for three radial positions on the ring. The erosion depth typically vanes from zero to $0.25 \mathrm{~mm}$, with a maximum measured depth of $0.75 \mathrm{~mm}$ (29.7 mils).

The total volume of material eroded from the inner and outer guard rings was estimated to be $0.3 \mathrm{~cm}^{3}$. Using a density of stainless steel of 7.75 $\mathrm{g} / \mathrm{cm}^{3}$ results in a mass loss estimate of $2.5 \mathrm{~g}$. If graphite had been used instead, the mass loss would have been approximately $1 \mathrm{~g}$ (assuming the same volume of material removed) and it would have taken nearly 4,000 hours to remove this material.

\section{Conclusions}

A thruster with anode layer (TAL) having an average discharge chamber diameter of $55 \mathrm{~mm}$ was tested on both a TsNIMMASH and U.S. hollow cathode. The perfomance of the D-55 anode layer thruster appears to be comparable to that of the SPT-100 thruster. A total of 636 hours of operation were accumulated on the D.55 before the test was terminated due to a failure of the thrust stand tilt control mechanism. No change in discharge current and voltage amplitudes, exhaust beam current density profile or engine performance was observed over this time. The components showing the most wear were the inner and outer ring magnet covers that serve to protect the electromagnets. The erosion data appear to have a roughly sinusoidal shape with the minimum erosion depths usually occurring at the clock angles corresponding to the locations of the electromagnets. Replacement of the stainless steel magnet covers used in the thruster tested with a more sputter resistant material should result in an engine with a useful service lifetime of greater than 5,000 hours.

\section{Acknowledgments}

The authors thank Mr. Allison Owens, Mr. Lew Pless, Mr. Robert Toomath and Mr. Keith Goodfellow for their assistance in assembling the experimental support hardware. The work described in this paper was performed by the Jet Propulsion Laboratory, California Institute of Technology, and was supported by the Ballistic Missile Defense Organization through an agreement with the National Aeronautics and Space Administration.

\section{References}

${ }^{\mathrm{I}}$ Garner, C. E., Polk, J. E, Pless, L. C., Goodfellow, K. D., and Brophy, J. R., "Performance Evaluation and Life Testing of the SPT-100," IEPC. 93-091, presented at the 23rd International Electric Propulsion Conference, Seattle, WA, September, 1993.

${ }^{2}$ Sankovic, J., Hamley, I., and Haag, T., "Performance Evaluation of the Russian SPT-100 Thruster at NASA LeRC," IEPC-93-094, presented at the 23rd International Electric Propulsion Conference, Seattle, WA, September, 1993.

${ }^{3}$ Garner, C. E. , Polk, J. E., and Brophy, J. R., "Cyclic Endurance Test of a SPT-100 Stationary Plasma Thruster," AIAA-94-2856, to be presented at the 30th Joint Propulsion Conference, Indianapolis, IN, June 1994.

${ }^{4}$ Arkhipov, B., et al., "SPT-100 Module Lifetime Test Results," AIAA-94-2854, to be presented at the 30th Joint Propulsion Conference, Indianapolis, IN, June 1994.

SLyapin, E. A., Garkusha, V. I., Semenkin, A. V., and Tverdokhlebov, S. O., "Anode Layer Thrusters: State-of-the-Art and Perspectives," IEPC93-228, presented at the 23rd International Electric Propulsion Conference, Seattle, WA, September, 1993.

${ }^{6}$ Caveny, L., Curran, F., and Brophy, J., "High Performance Electric Propulsion Systems to Meet Mission Opportunities," AIAA-94-2736, to be presented at the 30th Joint Propulsion Conference, Indianapolis, IN, June 1994.

${ }^{7}$ Sankovic, J., Haag, T., and Hamley, J., "Operating Characteristics of the Russian D-55 Anode Layer Thruster," AIAA-94-3011, to be presented at the 30th Joint Propulsion Conference, Indianapolis, $\mathbb{N}$, June 1994.

'Zharinov, A. V. and Popov, Yu, S., "Acceleration of Plasma by a Closed Hall Current," Sov. Phys. -- Tech. Phys., Vol. 12, pp. 208-211, August 1967.

${ }^{9}$ Yushamanov, E. E., "Radial Distribution on Potential in the Cylindrical Magnetic Trap for Ion Injection on the Magnetron Type," in Plasma Physics and the Problem of Controllable ThermoNuclear Reactions, Vol. 4, pp. 235-257, Academy of Sciences of the USSR, Moscow, 1958 (in Russian).

"Grishin, S. D, Yerofeyev, V. S., and Zharinov, A. V., "Accelerators with Closed Hall Current," in Plasma Accelerators, L. A. Artsymovich, ed, pp, 54-61, Mashinostroenie, Moscow, 1973 (in Russian).

"Grishin, S. D., Leskov, L. V., and Kozlov, N. P. Electric Thrusters, Mashinostroenic, Moscow, 1975 (in Russian). 
${ }^{12}$ Yerofeyev, V. S., Zharinov, A. V., and Lyapin, Ye. A., "Two-Stage Acceleration of Ionsin Layer with Closed Hall Currents," in Plasma Accelerators, L. A. Artsymovich, ed., pp. 54-61, Mashinostroenie, Moscow, 1973 (in Russian).

${ }^{13}$ Grishin, S. D., Yerofeyev, V. S., Zharinov, A. V., Naumkin, V. P., and Safronov, I. N., "Characteristics of Two-Stage Ion Accelerators with Anode Layer," Journal of Applied Mathematics and Technical Physics, No. 2, pp. 28-36, 1978 (in Russian).

${ }^{14}$ Grishin, S. D., and Leskov, L. V., Electric Thrusters of Spacecraft, Mashinostroenie, Moscow, 1989 (in Russian).

${ }^{15}$ Yerofeyer, V. S, and Lyapin, Ye. A., "Integral Characteristics of Ion Source of Hall Accelerator with Anode Layer," Abstracts for II AllUnion Conference on Plasma Accelerators, pp. 134135, Minsk, 1973 (in Russian).

${ }^{16}$ Lyapin, Ye. A., and Semenkin, A. V., "State-of-the-Art in Investigations of Anode Layer Accelerators," in Ion Injectors and Plasma Accelerators. pp. 20-33, Energoizdat, Moscow, 1990 (in Russian).

${ }^{17}$ Lyapin, Ye. A., and Pelepelin, Ye. V., "Ion Current Oscillations in Anode Layer Accelerator," Plasma Physics, Vol. 5, No. 3., pp. 600-606, 1979 (in Russian).

${ }^{18}$ Lyapin, Ye. A., Michailov, K. K, and Podgornova, V. D., "Oscillations in Single-Stage Anode Layer Accelerator," in Plasma Accelerators and Ion Injectors, pp, 21-22, Dnepropetrovsk, 1986 (in Russian).

${ }^{19}$ Lyapin, Ye. A. and Semenkin, A. V., "Accelerator with External Anode Layer," Abstracts for VII All-Union Conference on Plasama Accelerators and Ion Injectors, pp, 210-211, Charkov, 1989 (in Russian).

${ }^{20}$ Garkusha, V. I., Leskov, L. V., and Lyapin, Ye. A., "Plasma Accelerators with Anode Layers," in Plasma Accelerators and Ion Injectors with Anode Layers, pp. 129-138, Nauka, Moscow, 1984 (in Russian).

"Semenkin, A. V., "Investigation of Erosionin Anode Layer Thruster and Elaboration High Life Design Scheme," EPC-93-231, presented at the 23rd International Electric Propulsion Conference, Seattle, WA, September 1993.

${ }^{22}$ Haag, T. W. and Curran, F. M., "Arcjet Starting Reliability: A Multistart Test on Hydrogen/Nitrogen Mixtures," AIAA-87- 1061, May 1987 (see also NASA TM-898867). 


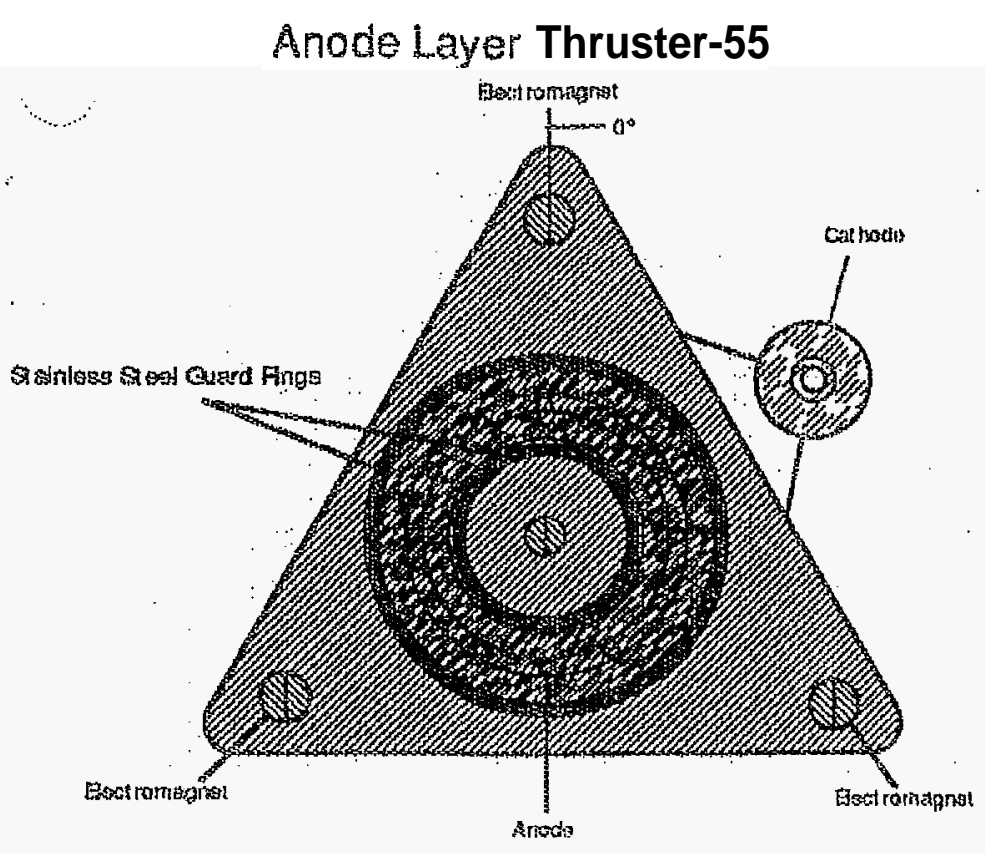

Fig. 1(a). Ancde Layer Thruster schematic.

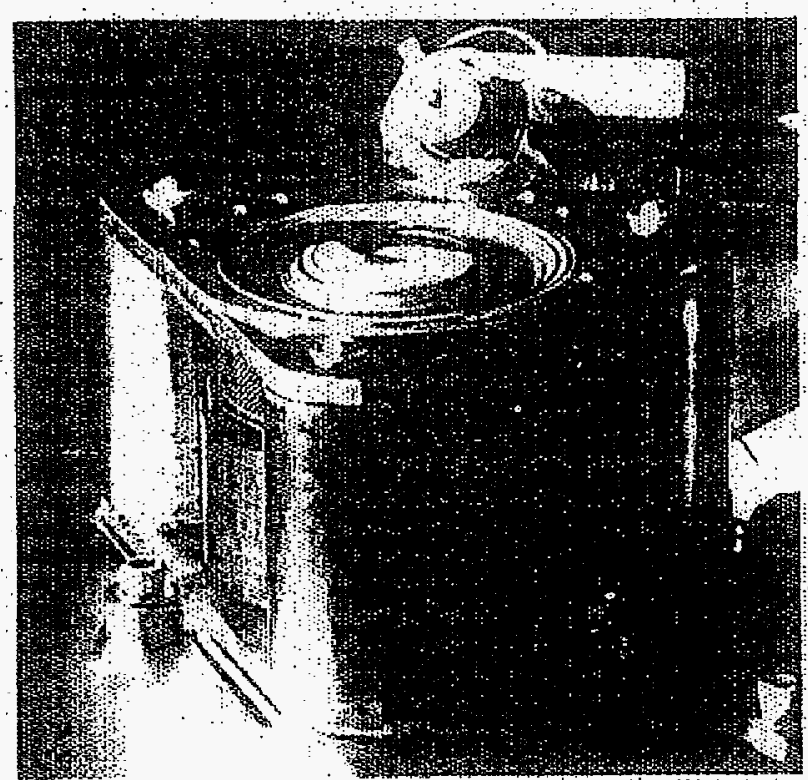

Fig. 1(c). Pre-test photograph with the JPL cathode.

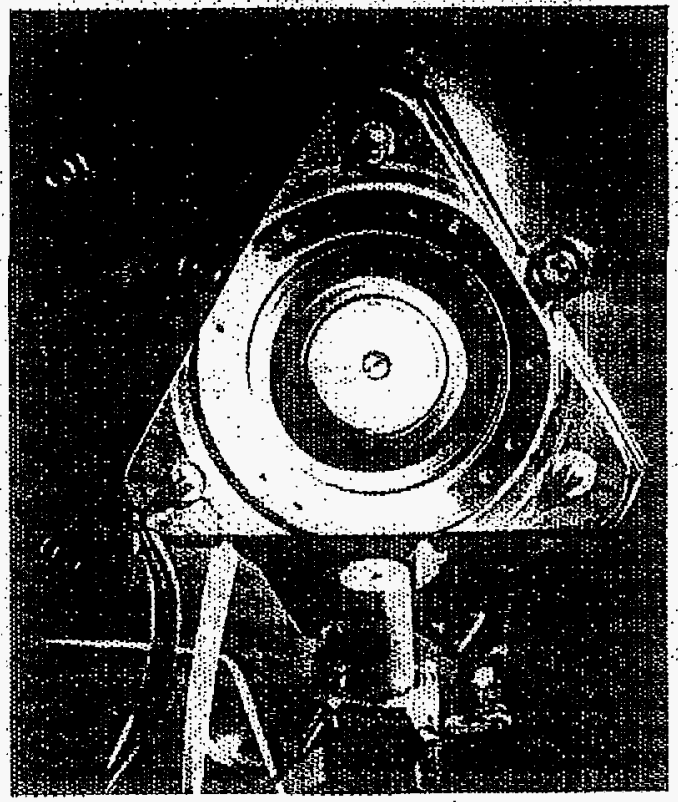

Fig. 1(b). Pre-rest photograph with the JPL cathode.

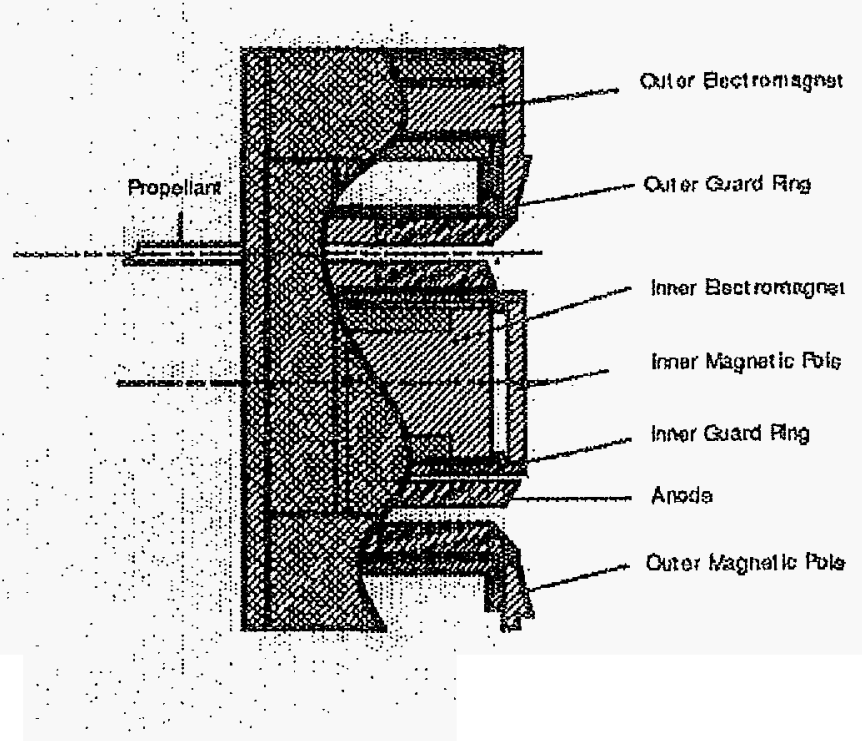

Fig. 2 Cross-section schematic of the D-55. 


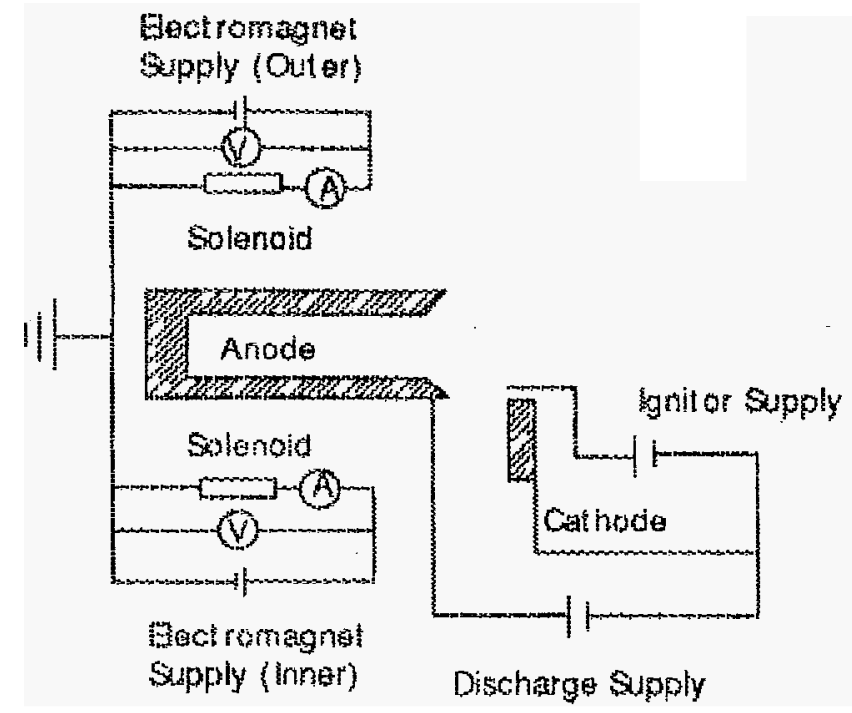

Fig. 3 fower supply systern schematic

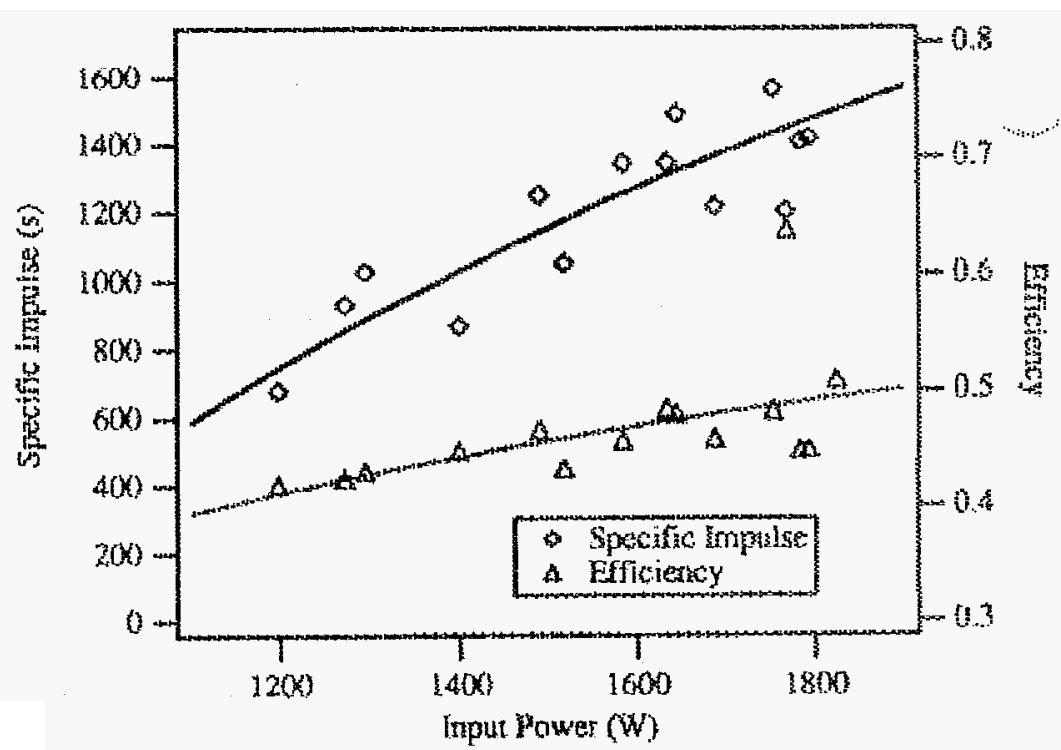

Fig. 4 Specif impulse and engine efficiency vs. inpu power (with JPi. cainowe).

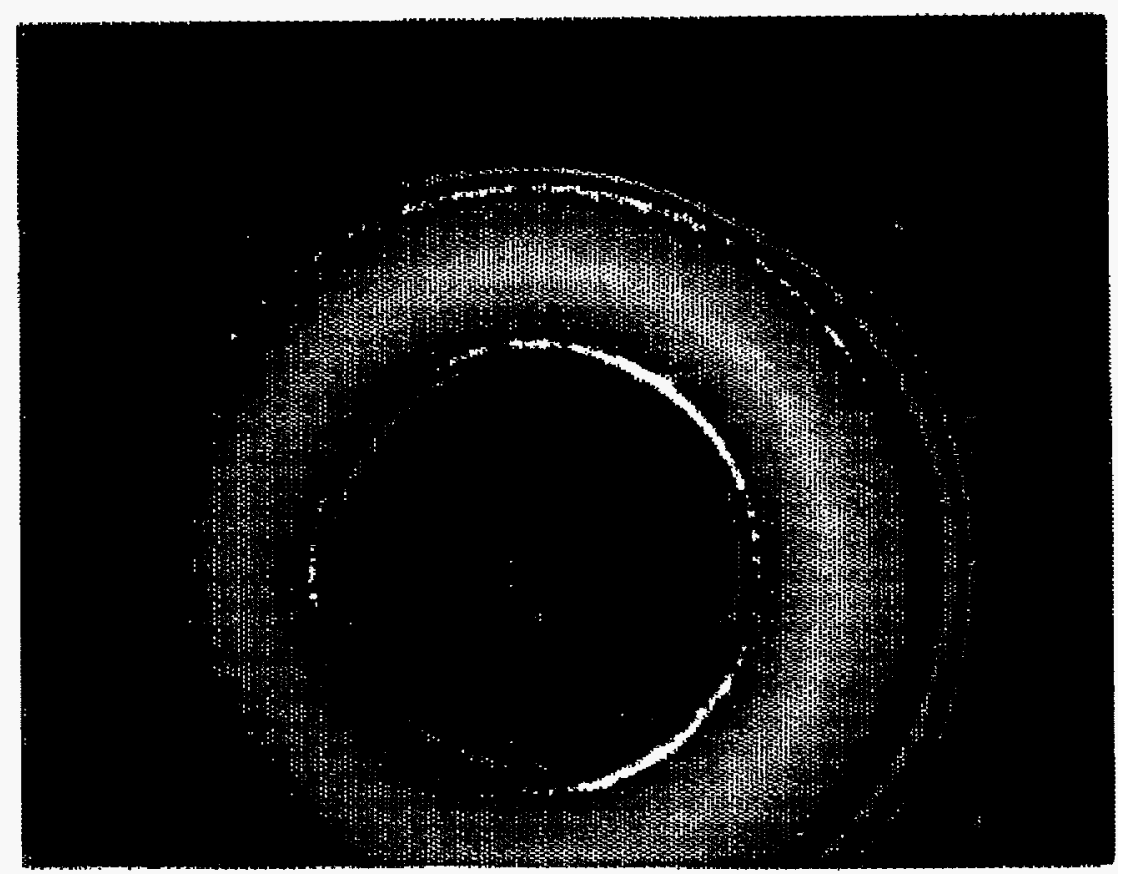

Fig, 5 The D 55 in operation. 


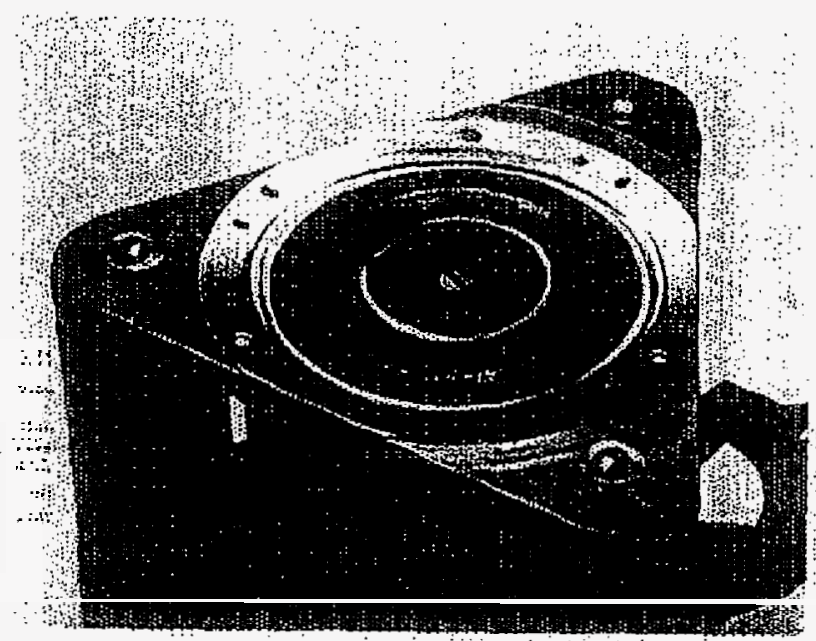

Fig. 6 Post wear test condition of the D-55 discharge chamber.

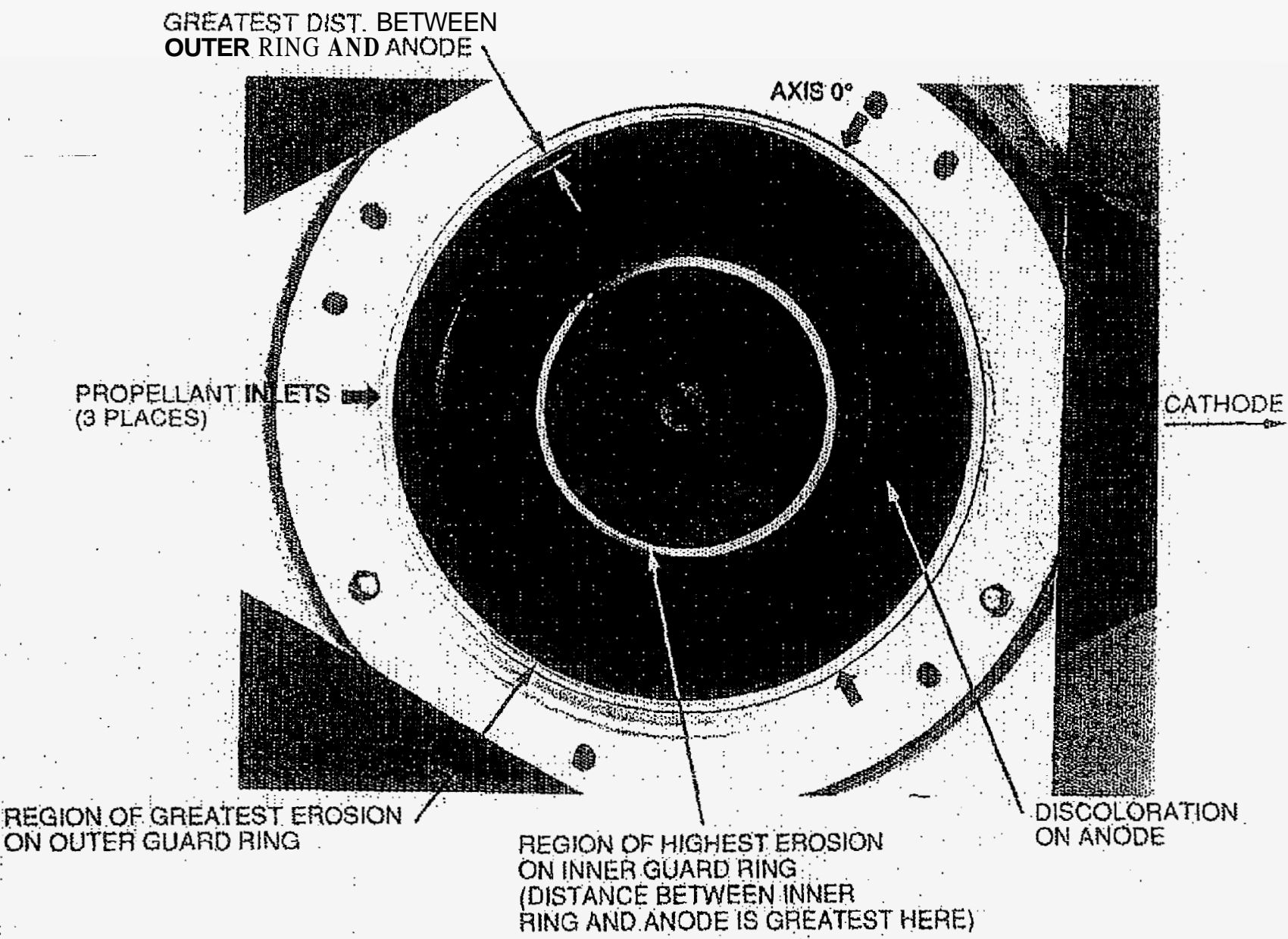

Fig. 7 Details of the D-55 erosion geometry. 


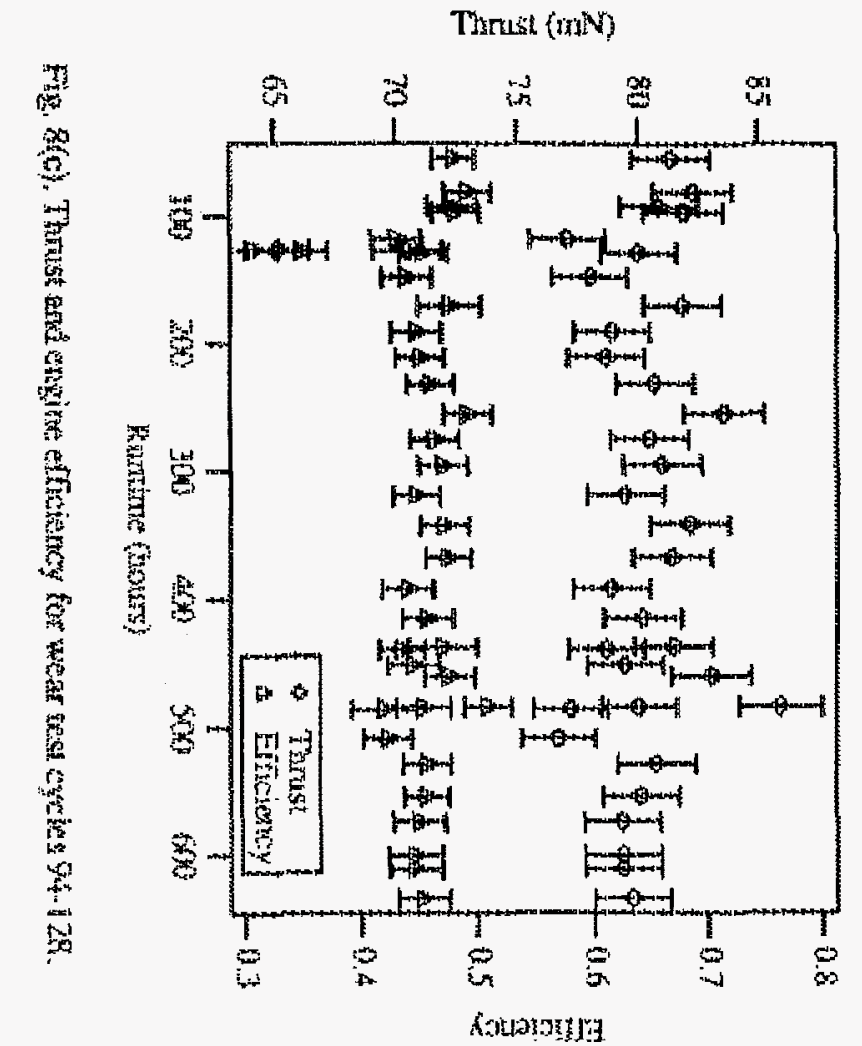

管

Discharge Curreat (A)

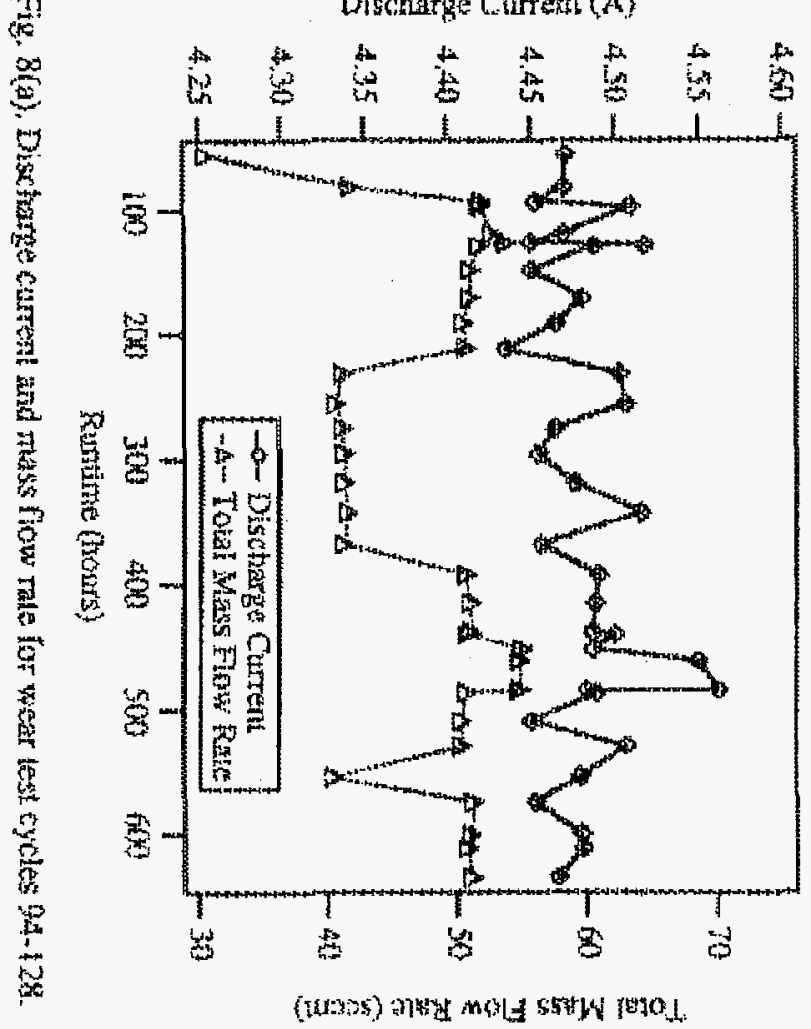

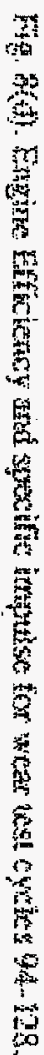

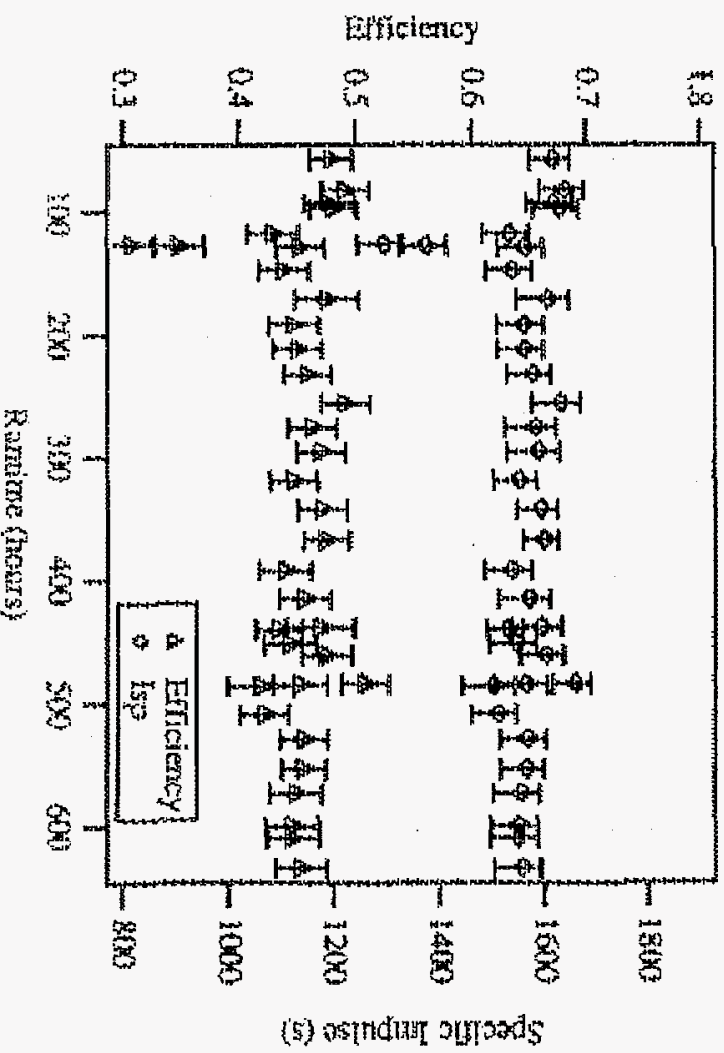

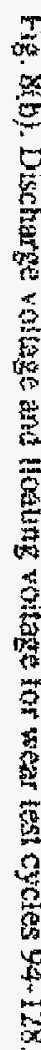

Dicuharge Yolitga (V)

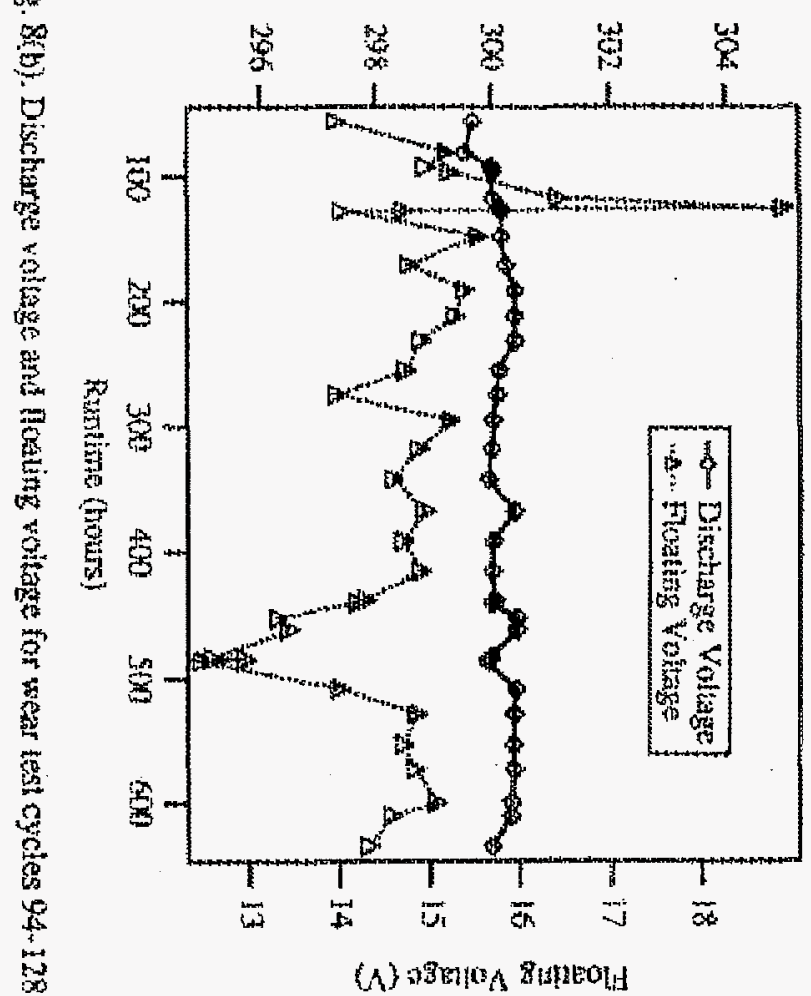




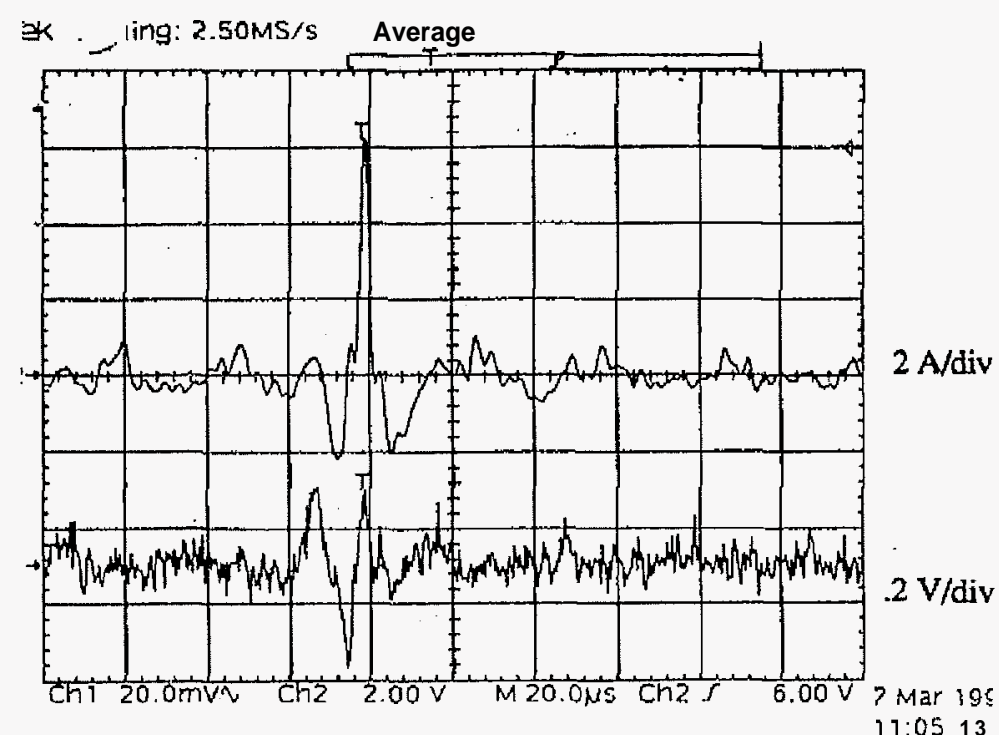

Fig. 9(a). Oscilloscope trace from cycle 95 taken just before engine shutdown.

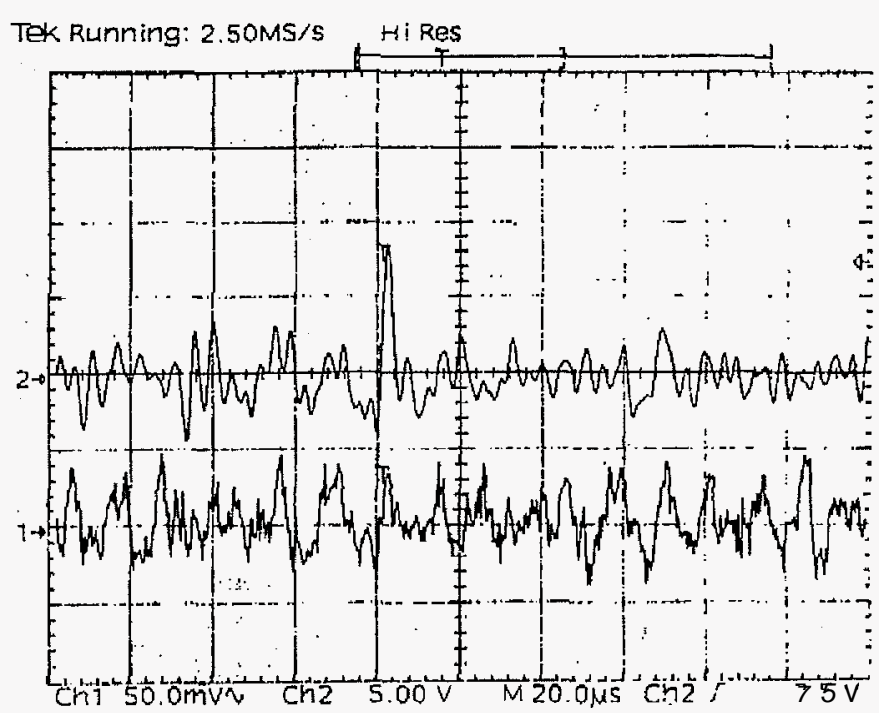

Fig. 9(b). Oscilloscope trace fromcycle 126 taken just before engine shutdown.

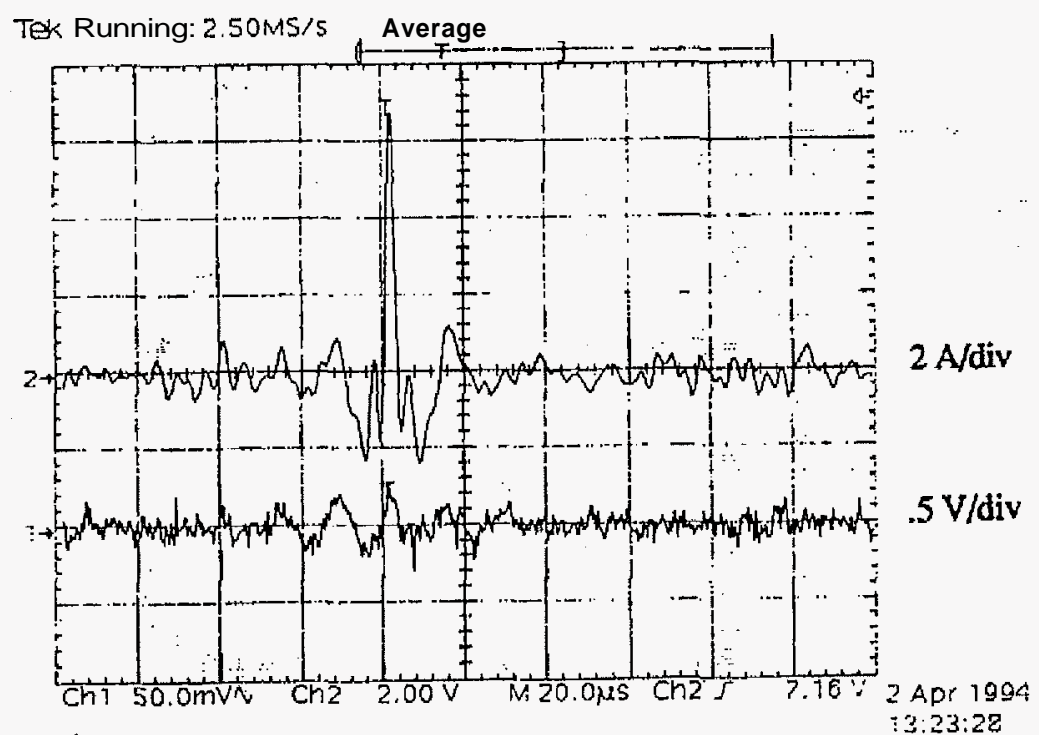

Fig. 9 (c). Oscilloscope trace fram cycle 126 takenjust before engine shutdown. 

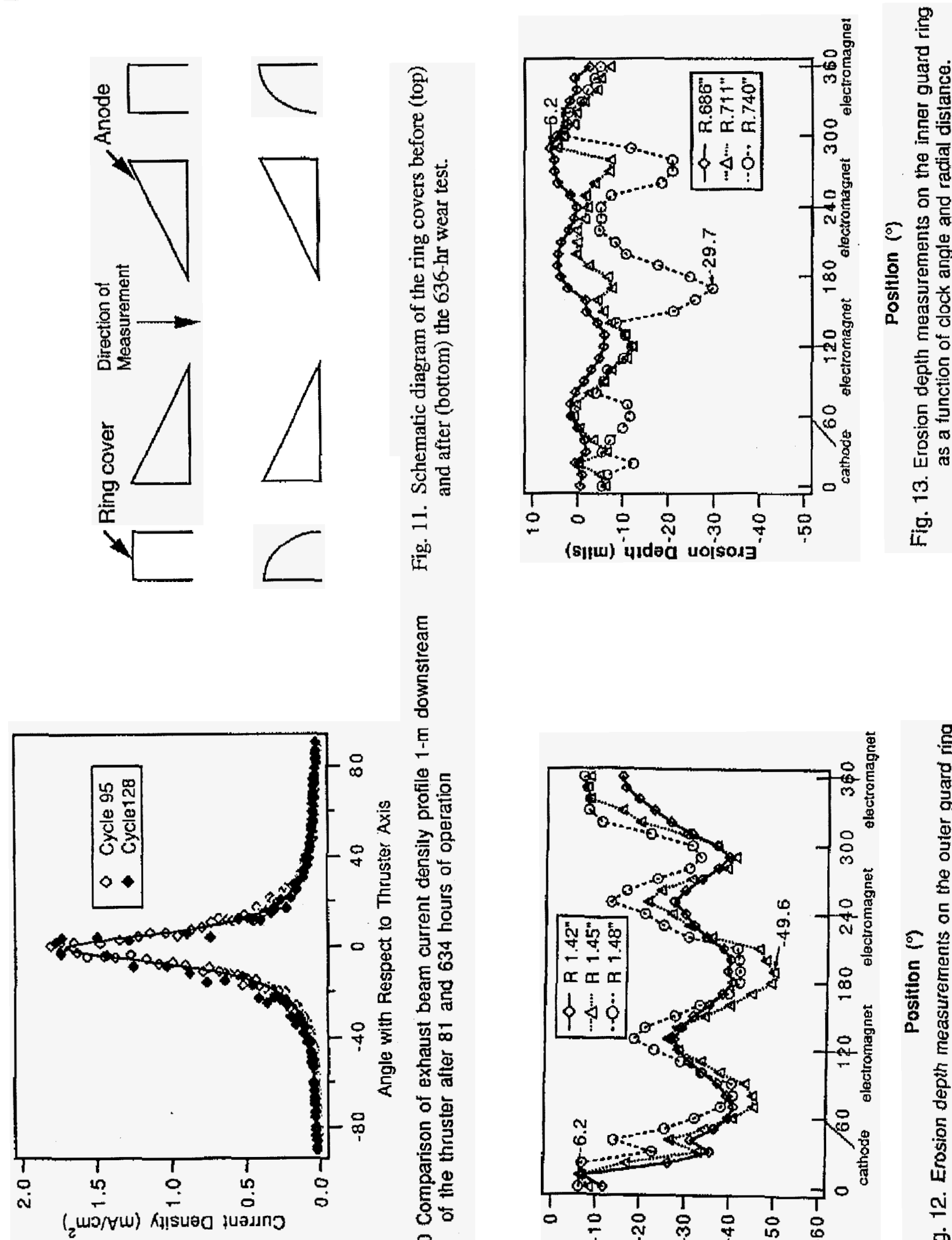

홍

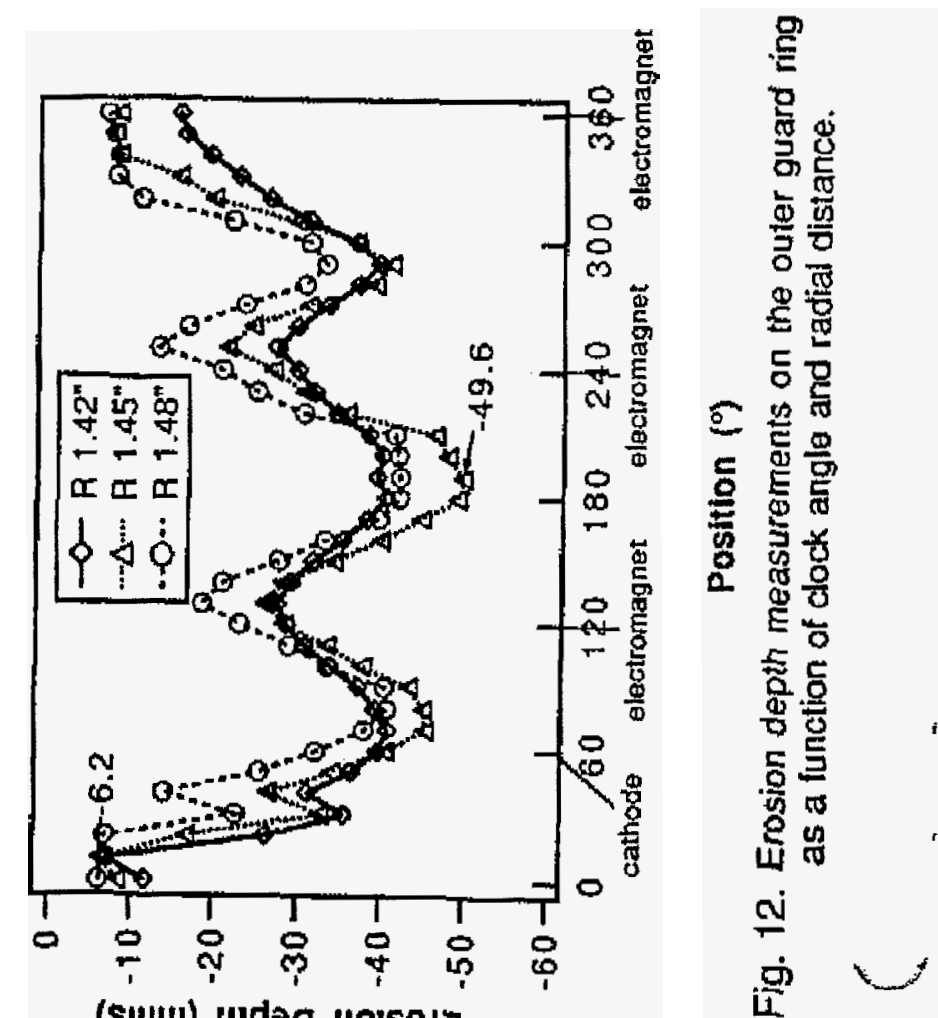

